\title{
ORIGENS DA ANTROPOLOGIA DA GRÉCIA ANTIGA: LÉVI-STRAUSS, VERNANT E DUAS VIAGENS DE 1935
}

José Otávio Nogueira Guimarães

Departamento de História - UnB

\begin{abstract}
Resumo
A comunicação inspira-se em considerações de Michel de Certeau que caracterizam a operação historiográfica como a "enigmática relação" que o historiador estabelece com a "sociedade presente e com a morte" pela "mediação de atividades técnicas". Ao tornar visível, no presente, aquilo que não é mais, o passado, a historiografia torna-se inscrição paradoxal da ausência no aqui e agora do texto histórico. Inspirase igualmente em tese de Jean-Pierre Vernant sobre a complementaridade, na Grécia arcaica, entre memorial funerário e canto épico; ambos operavam como formas de aculturação da morte. No jogo de estranhamento e afinidade entre os helenos antigos e nós, apresentam-se problemas, de ordem epistemológica e antropológica, que envolvem, em certos debates historiográficos contemporâneos, o estatuto do passado, a ideia do texto histórico como representação, a difícil conquista de uma consciência de historicidade e as tensas relações entre mito, memória e história no âmbito da tradição ocidental.
\end{abstract}




\section{I}

Logo após o fim da Segunda Guerra Mundial, depois de ter sido - segundo Hannah Arendt - "aspirado pela política" e "lançado no mundo da ação", já decepcionado com as posições que o Partido Comunista Francês tomara durante a Resistência, ${ }^{2}$ insatisfeito com o quadro político que se desenhava como uma liberação sob o comando do general De Gaulle e, sobretudo, indeciso quanto ao rumo a tomar em seu retorno à vida acadêmica, Jean-Pierre Vernant recebeu um convite para trabalhar no Brasil. A intenção era introduzi-lo na jovem universidade brasileira, a fim de que pudesse aqui realizar pesquisas e ensinar no ainda incipiente campo da antropologia. Convite similar ao que, uma década antes, Georges Dumas e Célestin Bouglé haviam feito a Claude Lévi-Strauss para que se tornasse etnógrafo e ministrasse sociologia na Universidade de São Paulo. ${ }^{3}$ Lembre-se que, filósofo de formação, como Lévi-Strauss, e cada vez mais psicólogo-historiador por conta da influência de Ignace Meyerson - com quem suas ligações pessoais haviam se estreitado durante os anos de guerra passados em Toulouse e a quem seria dedicado Mythe et pensée chez les Grecs (1965) -, Vernant não tinha ainda escolhido a Grécia antiga como domínio principal de estudos. Encontrava-se, nesse momento, em um vácuo acadêmico e existencial, em aparente suspensão, amadurecendo ou esperando decantar o que resultaria em suas futuras escolhas. Aliás, nesses anos sombrios do pré-guerra e da guerra, não havia muito espaço, de acordo com sua própria avaliação, para a tomada refletida de decisões:

...sem mesmo termos tido o sentimento de fazer uma escolha, encontrei-me lançado na frente de batalha. No curso dos acontecimentos, no quotidiano do mundo, alguma coisa acontecia que se nos impunha e nos ultrapassava. E o sentido da vida não se oferecia senão na medida em que existiam coisas que nos ultrapassavam. ${ }^{4}$

\footnotetext{
${ }^{1}$ É o que escreveu Arendt sobre uma geração de intelectuais franceses, situada entre o fim dos anos 1930 e o início dos anos 1940. ARENDT, Hannah. La crise de la culture - Huit exercices de pensée politique. Paris: Gallimard, 1972, p. 11-12.

${ }^{2}$ A propósito do descontentamento de Vernant com as posições do PCF, antes, durante e depois da Resistência, ver, por exemplo, VERNANT, Jean Pierre. La volonté de comprendre - Entretiens avec Jean-Pierre Vernant. Paris: Éditions de l'Aube 1999, p. 23-25 e 31-36; ver igualmente Idem. La traversée des frontières - Entre mythe et politique. Paris: Seiul, 2004, p. 24-25.

${ }^{3}$ Ver LÉVI-STRAUSS, Claude. Tristes tropiques. Paris: Plon, 1955, p. 78.

${ }^{4}$ VERNANT, Jean-Pierre. La traversée des frontières, op. cit., p. 21. Questionado, certa vez, sobre o que o teria ajudado a se manter firme durante os momentos mais duros da Resistência, em Toulouse, Vernant respondeu: "tenho certeza absoluta de que não havia como agir de outra
} 
Enfim, mesmo que tentado a partir para os trópicos - por conta das dificuldades de reinserção existencial, social e intelectual por que passava -, Vernant acabou por recusar o convite. Paul Rivet o fez desistir. ${ }^{5}$ Para ganhar a vida nesses anos, precisamente entre 1946 e 1948, Vernant dedicou-se a escrever artigos sobre a conjuntura política internacional em Action - hebdomadaire de l'indépendance française, ao mesmo tempo em que retomava sua atividade como professor de filosofia no Liceu Jacques Decourt, em Paris.

Na verdade, as razões pelas quais teria recusado a viagem e a temporada no Brasil são difíceis de serem estabelecidas com precisão. Imagina-se que deve ter se colocado algumas questões. Por um momento, "exilado político" em seu próprio país, valeria a pena desterrar-se em outro, tão distante, encarando um exílio ainda mais radical, longe de seu pequeno núcleo familiar recém-formado? Sem ter podido concluir sua tese de doutorado sobre a noção de trabalho em Platão, interrompida pelos acontecimentos de 1939, ele esperava poder retomar sua redação e continuar seus trabalhos no domínio da história da filosofia? Talvez não valesse a pena, nesse caso, mudar radicalmente de área de investigação. $\mathrm{O}$ fato é que ele disse não à possibilidade de, nessa ocasião, instalar-se no Brasil e tomar os "selvagens americanos" como seu novo objeto de estudos.

\section{II}

Lévi-Strauss, todavia, na década anterior, aceitara, mesmo odiando as viagens, partir para o Novo Mundo, onde se instalaria por alguns anos, para, cumprindo o ritual europeu de iniciação ao trabalho de campo além-mar, então etapa obrigatória e indispensável aos que pleiteavam profissionalizar-se na nova disciplina, transformar-se no mais influente etnólogo francês e um dos mais importantes nomes das ciências humanas da segunda metade do século XX. É relativamente bem conhecido o trecho de seus Tristes trópicos em que, no meio

maneira. Nem nos questionávamos". Idem. La volonté de comprendre, op. cit., p. 29.

5 "Foi somente em 1948 que solicitei auxílio para dedicar-me à pesquisa; que comecei a pensar em que poderia trabalhar"; VERNANT, Jean-Pierre. La volonté de comprendre, op. cit., p. 40. "Em 1946, ele sonhava com uma carreira idêntica àquela de Lévi-Strauss, mas Paul Rivet o dissuadiu de partir para o Novo Mundo; e ei-lo dirigindo sua atenção para a Grécia antiga, jogando finamente com o efeito da distância: longe e próximo, o universo helênico nos permite adaptar instrumentos teóricos para o entendimento da emersão da racionalidade". SPIRE, Antoine. Préface. In: VERNANT, Jean-Pierre. La volonté de comprendre, op. cit., p. 5-6. 
do Atlântico, em 1935, a bordo do navio que o conduzia ao Brasil, perguntavase sobre o sentido daquela viagem.

Eles ainda estariam ali para nos acolher; todos esses prodígios que testemunharam os navegadores de séculos passado? Ao percorrerem espaços virgens, esses viajantes estavam menos ocupados em descobrir um novo mundo do que em verificar o passado do antigo. Adão e Ulisses thes foram confirmados. ${ }^{6}$

Uma coisa parece certa: Lévi-Strauss não gostaria de reproduzir a experiência desses velhos viajantes e navegadores. Não gostaria muito menos que a etnologia resultante de suas observações de campo se transformasse em mais uma versão renovada da famosa Prière sur l'Acropole, de Auguste Renan. Nada, portanto, de reconfirmar Adão e Ulisses. "Melhor que Atenas - escrevia ainda nos Tristes trópicos -, o convés de um navio que navega para América oferece ao homem moderno uma acrópole para sua oração. Doravante, te recusamos, anêmica deusa, educadora de uma civilização enclausurada!". ${ }^{7}$ Ao comentar essas passagens, François Hartog mostrou que o jovem etnólogo esperava que sua empreitada intelectual pudesse justamente se constituir em uma "antioração na Acrópole": "acabara a viagem para Atenas e o milagre grego perdera muito de sua força e de seu brilho". 8

Lévi-Strauss escolhe, assim, os selvagens: não somente contra os antigos, mas igualmente contra os modernos que reproduzem os antigos ou simplesmente tomam esses últimos como origem ou infância de uma "civilização enclausurada". Se os selvagens americanos aparecem na cena cultural da Europa moderna capturados, em um primeiro momento, pela rede categorial herdada dos antigos, e, em um segundo momento, inseridos no regime evolucionista e progressista de uma temporalidade "burguesa", em um terceiro momento, tendem claramente a ser apreendidos em sua singularidade selvagem, em suas diferenças, contribuindo, mediante uma certa aproximação com os antigos, para marcar uma distância entre esses últimos e os modernos, condição de possibilidade para a emersão de uma primeira antropologia da Grécia antiga. Assim, Lévi-Strauss, tendo optado pelo Brasil e pelo selvagem contra a velha Atenas e sua tradição humanista etnocêntrica, preparou o terreno para que Vernant, ao

\footnotetext{
${ }^{6}$ LÉVI-STRAUSS, Claude. Tristes tropiques, op. cit., p. 78.

${ }^{7}$ Idem, p. 92.

${ }^{8}$ HARTOG, François. Anciens, modernes, sauvages. Paris: Galaade, 2005, p. 11.
} 
renunciar a fazer sua viagem aos trópicos, viesse a realizar sua opção intelectual pelo mundo grego antigo. Se Vernant não se torna portanto antropólogo por meio dos selvagens, sua démarche pressupõe esse regard éloigné, herança dessa tradição etnológica.

Para ilustrar essa perspectiva vernantiana, tomemos apenas um exemplo. Por ocasião de uma conferência, em 1966, ao reconhecer a presença crescente de "alteridades" na cultura europeia, Vernant relativiza as pretensões universalizantes e acrônicas de sua tradição intelectual, o que o leva a rever igualmente a eficácia da aparelhagem conceitual marxista de análise histórica, na qual havia, em parte, se formado:

...encontramo-nos, com efeito, confrontados e associados a humanidades que são em todos os planos distintas da nossa. Distintas por sua religião, seu sistema de valores, seu nível técnico, distintas por suas formas de vida social e de existência pessoal. A cada dia vivendo mais em comunidade com esses homens - mesmo se eles conhecem ainda a fome ao passo que nós uma relativa abundância - estamos, sob seus olhares, inclinados a nos vermos com seus olhos. Encontram-se assim questionados certos traços que pensávamos consubstanciais à natureza humana...

E ele ainda acrescenta:

...o marxismo também deve se questionar. Em que medida uma teoria científica oriunda de uma reflexão sobre as sociedade industriais do Ocidente pode ser aplicada diretamente a civilizações de um outro tipo? Em que medida os fatos econômicos e as relações sociais ainda participam da mesma maneira de conjuntos sociais distintamente organizados? ${ }^{9}$

Em resumo, a Atenas de Vernant, depois da viagem de Lévi-Strauss, não é certamente mais aquela de Renan e do milagre grego.

\section{III}

Nesse sentido, é bastante curioso que, nesse mesmo ano de 1935 em que Lévi-Strauss navegava rumo ao Novo Mundo, Vernant tomava uma embarcação bem menor - não no Atlântico, mas no Mediterrâneo - na direção justamente do Velho Mundo. O pequeno barco partiu do Cairo para ancorar no Pireu, o porto

\footnotetext{
${ }^{9}$ VERNANT, Jean-Pierre. Morale, histoire et société. In: Religions, histoires, raisons. Paris: François Maspero, 1979, p. 75-76.
} 
de Atenas. Vernant contou inúmeras vezes a história dessa viagem. ${ }^{10}$ Ele, seu irmão Jacques e mais dois camaradas pecorreram a Grécia a pé: "quatro jovens cheios de vida, saudáveis, de bermuda e mochila nas costas" ${ }^{11}$ Tratava-se ainda, felizmente para eles, de uma Grécia anterior à agressiva indústria do turismo. ${ }^{12}$ "Éramos", relembra Vernant, "acolhidos por camponeses. Receber um hóspede estrangeiro, mais que um dever aparecia [para esses camponeses] como uma chance, um favor divino que não se podia deixar escapar". ${ }^{13}$

Novamente, não se trata de nada que se assemelhe à Acrópole ateniense da Prière de Renan: o "favor divino" pelo qual camponeses gregos exerciam sua hospitalidade distingue-se completamente do culto moderno e contemporâneo, filológico e estético, sobretudo o do século XIX e ainda em curso no século XX, que uma certa elite europeia passou a devotar à "anêmica deusa, educadora de uma civilização enclausurada". ${ }^{14}$ A viagem a Atenas de Vernant não foi portanto aquela de arqueólogos e helenistas formando-se nos padrões do realismo epistemológico da Altertumswissenschaft ${ }^{15}$ não foi muito menos uma etapa, realizada com certo atraso, do conhecido grand tour, pelo qual a aristocracia europeia, já a partir da segunda metade do século XVIII, educava seus jovens humanistas. ${ }^{16}$ Vernant é explícito nesse sentido: o que o encantou foram, em primeiro lugar, certas características naturais do Mediterrâneo, do Egeu em

\footnotetext{
${ }^{10}$ Por exemplo, VERNANT, Jean-Pierre. Entre mythe et politique. Paris: Seuil, 1996, p. 32; Idem. La volonté de comprendre, op. cit., p. 37-39; Épilogue. In: VERNANT, Jean-Pierre \& ROMILLY, J. de. Pour l'amour du grec. Paris: Bayard, 2000, p. 167-169; VERNANT, Jean-Pierre. La traversée des frontiers - Entre mythe et politique. Paris, Seuil, 2004, p. 23-24.

${ }^{11}$ VERNANT, Jean-Pierre. La traversée des frontières, op. cit., p. 23-24.

${ }^{12}$ Vernant diz, no final dos anos 1990, referindo-se implicitamente a essa indústria e ao crescimento urbano desordenado de Atenas: "Hoje, o Pireu, como Atenas, é monstruoso, mas antes era maravilhoso". VERNANT, Jean-Pierre. La volonté de comprendre, op. cit., p. 38.

${ }^{13}$ VERNANT, Jean-Pierre. La traversée des frontières, op. cit., p. 24.

${ }^{14}$ LÉVI-STRAUSS, Claude. Tristes tropiques, op. cit., p. 92.

${ }^{15}$ Ver MARCHAND, Suzanne. Down from Olympus: archaeology and philhellenism in Germany, 1750-1970. Princepton: Princepton University Press, 1996; GRAFTON, Anthony. Polyhistor into philolog: Notes on the transformation of german classical scholarship, 1780-1850. History of universities 3. 1983, p. 159-192.

${ }^{16}$ Sobre o grand tour, basta citar BURGESS, Anthony \& HASKELL, Francis. Le grand siècle du voyage. Paris: Albin Michel, 1968; BUZARD, James. The grand tour and after (1660-1840). In: HULME, P. \& YOUNGS, T. (ed.). The Cambridge companion to travel writing. Cambridge (UK) \& New York: Cambridge University Press, 2002, p. 37-52; AMPOLO, Carmine. Studiosi ed avventutieri nel XVIII secolo: tra storia universale, storia greca ed erudizione. Storie greche: la formazione della moderna storiografia sugli antichi Greci. Torino: Einaudi, 1997, p. 113-132.
} 
particular: "os odores, a cor do céu, o brilho desse firmamento grego". ${ }^{17}$ Basta ver as impressões que guardou do Pireu, a parada inicial: "foi a descoberta de um pequeno porto oriental incrivelmente vivaz, colorido, cheio de cheiros, sem carros; com asnos, charretes e nenhuma casa nas colinas do entorno". ${ }^{18}$ Uma Grécia física, sentimental e plena de calor humano, ainda não constituída em objeto intelectual, marcara assim essa primeira experiência de Vernant com o mundo helênico. "As ruinas antigas, essas velhas pedras - escreveu - isso não me interessava: o que queria ver era o povo grego", ${ }^{19}$ pode-se dizer, o homem grego.

Esse homem grego, Vernant o reencontraria alguns anos mais tarde, agora, contudo, já transformado em objeto de estudo acadêmico, em tema de pesquisas. Não se tratava mais, evidentemente, do grego contemporâneo, mas do homem grego antigo. Se, meio século depois, Vernant admite que essa juvenil viagem a Grécia pode ter desempenhado certo papel, sem que ele se desse exatamente conta disso, em sua escolha, em fins dos anos 1940, pelo helenismo, não foi essa viagem cheia de aventuras o motivo central de sua adesão aos estudos gregos. Além de suas primeiras leituras de Platão (que o encantara, mas que ele havia encarado metodologicamente pelo prisma de uma história da filosofia tradicional e com uma problemática de fundo de forte inspiração marxista), e do esforço para fugir ao controle intelectual do Partido Comunista Francês (controle que o incomodaria muito mais caso se dedicasse a temas da atualidade), o que o conduziu, fundamentalmente, a escolher "cientificamente" a Grécia antiga foi o encontro, em 1948, com Louis Gernet, recém-chegado a Paris, após anos de exílio argelino. "Foi uma paixão fulminante", escreve Vernant, "Gernet mudou completamente minha maneira de ver as coisas". ${ }^{20}$

Louis Gernet - a quem foi dedicado As origens do pensamento grego (1962) - representou para Vernant, e não há razão para se deter longamente nessa relação, ${ }^{21}$ além de seu "saber excepcional", "sua abertura de espírito", além de sua recusa da erudição vazia, seca e diletante do classicismo tradicional, ${ }^{22}$ a conjunção, de tantas ressonâncias vindouras, entre as ciências sociais e o helenismo. Pode-se simplificar o essencial desse encontro dizendo que Gernet

\footnotetext{
${ }^{17}$ VERNANT, Jean-Pierre. La volonté de comprendre, op. cit., p. 37.

${ }^{18}$ Idem, p. 38.

${ }^{19}$ Idem, ibid.

${ }^{20}$ VERNANT, Jean-Pierre. La traversée des frontières, op. cit., p. 24.

${ }^{21}$ Pelo simples fato de que ela já foi inúmeras vezes explorada.

${ }^{22}$ VERNANT, Jean-Pierre. La volonté de comprendre, op. cit., p. 40.
} 
representou um modo antropológico de tratar a Grécia antiga, uma renovação metodológica capaz de atualizar a ideia de humanismo. ${ }^{23}$ Vernant, aliás, insistiu nesse ponto: "por meio dele, sem que os helenistas contemporâneos tivessem muita consciência disso, operou-se a passagem, com todas as suas implicações e consequências, do humanismo tradicional - aquele do milagre grego - a uma antropologia histórica". ${ }^{24}$ Em suma, o encontro Gernet-Vernant significou, no domínio particular dos estudos gregos franceses, a possibilidade de sobrevivência, na segunda metade do século $\mathrm{XX}$, de uma antropologia do campo simbólico, criticada e mal-falada até então, que, além de Gernet, contava, na primeira metade do século XX, com as contribuições fundamentais de Marcel Mauss, Marc Bloch e Marcel Granet. ${ }^{25}$ Foi sob a orientação dessa perspectiva que Vernant passou dez anos "fazendo-se" helenista, ao mesmo tempo em que assegurava o secretariado do Journal de Psychologie, revista que funcionou como uma espécie de "encruzilhada das ciências humanas" francesas no entreguerras, como bem mostrou Riccardo Di Donato. ${ }^{26}$ É notório que Vernant não percorreu as "vias naturais" para a formação de um helenista acadêmico, não tendo percorrido as etapas de iniciação ao métier exigidas para os que pretendiam fazer carreira no meio dos classicistas. Ele conseguiu se estabelecer na "marginalidade prestigiosa" do sistema universitário francês (Grandes Écoles - Collège de France), instituições que acolheriam progressivamente, na segunda metade do século XX, as pesquisas oriundas das ciências sociais que revolucionariam o território hexagonal das humanidades.

\footnotetext{
${ }^{23}$ Ver GERNET, Louis. De la modernité des anciens [1939]. Les Grecs sans miracle - Textes 1903-1960. Textes réunis par R. Di Donato, préface de Jean-Pierre Vernant. Paris: François Maspero, 1983, p. 344-355.

${ }^{24}$ VERNANT, Jean-Pierre. Les Grecs sans miracle de Louis Gernet [1983]. Entre mythe et politique, op. cit., p. 195.

${ }^{25}$ Ver FABRE, Daniel. Le symbolique, brève histoire d'un objet. In: REVEL, J. \& WACHTEL, N. (texts rassemblées par). Une école pour les sciences sociales: de la VI Section à l'École des Hautes Études em Sciences Sociales. Paris: Cerf/Éditions de l'EHESS, 1996, p. 229-250; DI DONATO, Riccardo. L'anthropologie historique de Louis Gernet. In: Annales ESC 37, 5/6, 1982, p. 984-996. ${ }^{26}$ DI DONATO, Riccardo. Le Journal de Psychologie de Meyerson: au carrefour des sciences de l'homme. In: PAROT, F. (textes reunis et publiés par). Pour une psychologie historique - Écrits en hommage à Ignace Meyerson. Paris: PUF, 1996, p. 119-130.
} 


\section{IV}

Destaquemos que a antropologia de Vernant, ao não se construir a partir do selvagem como objeto primeiro, mas mediante um mergulho na Grécia antiga, contribuiu de certo modo para o movimento contemporâneo de amplificação do objeto etnológico. Objeto que, paulatinamente, ao se destacar de sua redução ao exótico, do selvagem de além ou aquém-mar, veio integrar o que se poderia chamar genericamente de as formas variadas da diferença. Vernant e Lévi-Strauss, cada qual ao seu modo, participaram da descoberta dessa ideia de que é a abordagem e não propriamente o objeto que define a perspectiva antropológica. ${ }^{27}$ Arriscamos afirmar que Vernant contribuiu assim, indiretamente, para o desenvolvimento do que os historiadores anglo-saxões da antropologia viriam a chamar, no jargão dessa comunidade, de "pesquisa at home" ${ }^{28} \mathrm{Na}$ verdade, no meio intelectual metropolitano, essa expressão, não faz muito tempo, parecia parodoxal, uma contradição em termos. A passagem de Vernant na conferência de 1966, citada acima, já era sintomática da diminuição acelerada da distância entre etnólogos e pesquisadores de campo - considerados, por um certo tempo, apenas como "informantes". Não foi preciso Vernant escutar Clifford Geertz proclamar, em 1983, "somos todos indígenas", ${ }^{29}$ para que se lançasse em sua antropologia histórica da Grécia antiga; antropologia que poderia muito bem se encaixar no que Michel Foucault chamou de "uma etnologia interna da cultura ocidental". ${ }^{30}$ Em 1939, um antropólogo do calibre de Malinovski já não dizia, ao prefaciar o livro de um de seus alunos de origem chinesa decidido a estudar os camponeses de seu país, que "uma antropologia de seu próprio povo era uma conquista árdua, porém muito mais preciosa".31

\footnotetext{
${ }^{27}$ Lévi-Strauss, ao constatar, no início dos anos 1960, um medo generalizado relativo ao desaparecimento do objeto da antropologia (a eliminação ou descaracterização de populações "primitivas" por contato), reagiu sugerindo que a disciplina deixasse de se definir em termos absolutos como estudo dos "primitivos" e passasse a ser concebida como um tipo de relação entre o observador e observado. LÉVY-STRAUSS, Claude. La crise moderne de l'anthropologie. Le Courrier XIV, 11, 1961, p. 12-17. ${ }^{28}$ Sobre o desenvolvimento dessa noção de "pesquisa at home" e a propósito de seu impacto sobre o estatuto da disciplina etnologia, ver PEIRANO, Mariza. Antropologia at home. [1998]. A teoria vivida e outros ensaios de antrpopologia. Rio de Janeiro: Jorge Zahar Ed., 2006, p. 37-52.

${ }^{29}$ GEERTZ, Clifford. Savoir local, savoir global: les lieux du savoir [1983]. Paris: PUF, 1986, p. 188. ${ }^{30}$ FOUCAULT, Michel. Sur les façons d'écrire l'histoire [1967]. In: Dits et écrits 1, 1954-1975 [1994]. Paris: Gallimard, 2001, p. 626.

${ }^{31}$ MALINOWSKI, Bronislaw. Preface. In: H-T., Fei. Peasant life in China: A field study of country life in the Yangtze valley. Paris: Plon, 1939, p. xiv.
} 
No fim de sua vida, principalmente em seu último trabalho, La traversée des frontières, Vernant foi ainda mais longe ao se tornar antropólogo-historiador dele mesmo, de seu engajamento como homem de ação na história contemporânea e de seu trabalho como helenista:

Na medida em que deixei de seu um ator histórico (...) e devido ao fato de me ter tornado um antropólogo da Grécia antiga, meu olhar se modificou. Se tivesse simplesmente entrado na Resistência sem que, em seguida, tivesse me dedicado aos estudos gregos, não veria em meu papel, minha ação, meu engajamento resistente o que vejo aí como historiador, agora, no momento em que reflito sobre o que os próprios gregos contavam na Ilíada. ${ }^{32}$

Essa dimensão reflexiva, conquista do discurso das ciências sociais nas últimas décadas, é um dos elementos fundamentais, senão o principal, que poderia explicar a importância de Vernant para os frutíferos intercâmbios entre história e antropologia na segunda metade do século XX.

\section{Referências bibliográficas}

AMPOLO, Carmine. Storie greche: la formazione della moderna storiografia sugli antichi Greci. Torino: Einaudi, 1997.

ARENDT, Hannah. La crise de la culture - Huit exercices de pensée politique [1961-1968]. Tradução de P. Lévy. Paris: Gallimard, 1972.

BURGESS, Anthony \& HASKELL, Francis. Le grand siècle du voyage. Paris: Albin Michel, 1968.

BUZARD, James. The grand tour and after (1660-1840). In: HULME, P. \& YOUNGS, T. (ed.). The Cambridge companion to travel writing. Cambridge (UK) \& New York: Cambridge University Press, 2002, p. 37-52.

DI DONATO, Riccardo. L'anthropologie historique de Louis Gernet. Annales ESC 37, 5/6. 1982, p. 984-996.

DI DONATO, Riccardo. Le Journal de Psychologie de Meyerson: au carrefour des sciences de l'homme. In: PAROT, F. (textes réunis et publiés par). Pour une psychologie historique - Écrits en hommage à Ignace Meyerson. Paris: PUF, 1996, p. 119-130.

FABRE, Daniel. Le symbolique, brève histoire d'un objet. In: REVEL, J. \& WACHTEL, N. (textes rassemblées par). Une école pour les sciences sociales: de la VI ${ }^{\mathrm{e}}$ Section à l'École des Hautes Études en Sciences Sociales. Paris: Cerf/ Éditions de l'EHESS, 1996, p. 229-250.

\footnotetext{
${ }^{32}$ VERNANT, Jean-Pierre. La traversée des frontières, op. cit., p. 22.
} 
FOUCAULT, Michel. Dits et écrits 1, 1954-1975 [1994]. Paris: Gallimard, 2001.

GEERTZ, Clifford. Savoir local, savoir global: les lieux du savoir [1983]. Paris: PUF, 1986.

GERNET, Louis. Les Grecs sans miracle - Textes 1903-1960. Textes réunis par R. Di Donato, préface de J.-P. Vernant. Paris: François Maspero, 1983.

GRAFTON, Anthony. Polyhistor into philolog: Notes on the transformation of german classical scholarship, 1780-1850. History of universities 3, 1983, p. 159-192.

HARTOG, François. Anciens, modernes, sauvages. Paris: Galaade, 2005.

LÉVI-STRAUSS, Claude. Tristes tropiques. Paris: Plon, 1955.

LÉVI-STRAUSS, Claude. La crise moderne de l'anthropologie. Le Courrier XIV, 11, 1961, p. 12-17.

MALINOWSKI, Bronislaw. Preface. In: H.-T., Fei. Peasant life in China: a field study of country life in the Yangtze valley. New York: E. P. Dutton, 1939, p. IX-XXVI.

MARCHAND, Suzanne. Down from Olympus: archaeology and philhellenism in Germany, 1750-1970. Princepton: Princepton University Press, 1996.

PEIRANO, Mariza. Antropologia at home [1998]. In: A teoria vivida e outros ensaios de antropologia. Rio de Janeiro: Jorge Zahar, 2006, p. 37-52.

SPIRE, Antoine. Préface. In: VERNANT, J.-P. La volonté de comprendre: entretiens avec Jean-Pierre Vernant. Paris: Éditions de l'Aube, 1999, p. 5-9.

VERNANT, Jean-Pierre. Religions, histoires, raisons. Paris: François Maspero, 1979.

VERNANT, Jean-Pierre. Entre mythe et politique. Paris: Seuil, 1996.

VERNANT, Jean-Pierre. La volonté de comprendre - Entretiens avec Jean-Pierre Vernant. Paris: Éditions de l'Aube, 1999.

VERNANT, Jean-Pierre. Pour l'amour du grec. Ouvrage présenté par J.-P. Vernant \& J. de Romilly. Paris: Bayard, 2000.

VERNANT, Jean-Pierre. La traversée des frontières - Entre mythe et politique 2. Paris: Seuil, 2004. 